\title{
Characterization of Pseudomonas aeruginosa isolates obtained from patients in Canadian hospitals: Results of the CANWARD 2007 study
}

\author{
Andrew Walkty MD ${ }^{1}$, Melanie DeCorby $\mathrm{MSc}^{2}$, Kim Nichol $\mathrm{MSc}^{1}$, Melissa McCracken MSc ${ }^{3}$, \\ Michael R Mulvey $\mathrm{PhD}^{3}$, James A Karlowsky PhD ${ }^{1,2}$, Daryl J Hoban $\mathrm{PhD}^{1,2}$, George G Zhanel $\mathrm{PhD}^{1,2}$
}

A Walkty, M DeCorby, K Nichol, et al. Characterization of Pseudomonas aeruginosa isolates obtained from patients in Canadian hospitals: Results of the CANWARD 2007 study. Can J Infect Dis Med Microbiol 2009;20(Suppl A):54A-58A.

INTRODUCTION: Pseudomonas aeruginosa is an important nosocomial pathogen. The purpose of the present study was to evaluate the antimicrobial susceptibility profile of $P$ aeruginosa isolates obtained from patients in different areas of Canadian hospitals.

METHODS: From January to December 2007 inclusive, 12 sentinel hospitals across Canada submitted clinical isolates from patients attending emergency rooms, medical wards, surgical wards and intensive care units (ICUs) (the Canadian Ward Surveillance Study [CANWARD 2007]). Each centre was asked to submit clinical isolates (consecutive, one per patient per infection site) from blood $(n=360)$, respiratory $(n=200)$, urine $(n=100)$ and wound/intravenous $(n=50)$ infections. Susceptibility testing was performed using Clinical and Laboratory Standards Institute broth microdilution methods. Multidrug-resistant (MDR; resistant to at least three different antimicrobial classes) isolates were typed by pulsed-field gel electrophoresis. RESULTS: In total, $451 \mathrm{P}$ aeruginosa isolates were collected (representing 7\% of all CANWARD 2007 isolates). The rank order of antimicrobial susceptibility was as follows (percent susceptible): amikacin $(93.1 \%)=$ piperacillin/tazobactam $(93.1 \%)>$ meropenem $(87.4 \%)>$ cefepime $(69.4 \%)>$ ciprofloxacin $(67.2 \%)>$ gentamicin $(66.1 \%)>$ levofloxacin (60.5\%). Reduced susceptibility to cefepime, meropenem and levofloxacin was observed more frequently among ICU isolates $(\mathrm{P}<0.05)$. Thirty-four isolates $(7.5 \%)$ were MDR. MDR isolates were more likely to be obtained from patients in an ICU $(\mathrm{P}=0.003)$ and less likely to come from a bloodstream source $(\mathrm{P}=0.008)$. Excluding colistin (polymyxin E), amikacin and piperacillin/tazobactam, followed by meropenem, were the most active antimicrobials evaluated versus the MDR isolates. All of the MDR isolates were susceptible to colistin. The majority of MDR isolates were genetically unrelated.

CONCLUSIONS: $P$ aeruginosa is common among clinical specimens from patients in Canadian hospitals. Of the antipseudomonal antimicrobials evaluated, amikacin, meropenem and piperacillin/tazobactam demonstrated the greatest in vitro activity. Isolates with reduced antimicrobial susceptibility and MDR isolates were more often obtained from ICU patients. All of the MDR isolates remained susceptible to colistin.

Key Words: Antimicrobial resistance; Multidrug-resistant; Pseudomonas aeruginosa

Ps seudomonas aeruginosa is an important cause of nosocomial bloodstream, urinary tract, wound and respiratory infections (1). In recent years, $P$ aeruginosa clinical isolates resistant to multiple classes of antimicrobial agents have become
La caractérisation des isolats de Pseudomonas aeruginosa obtenus de patients d'hôpitaux canadiens : Les résultats de l'étude CANWARD 2007

INTRODUCTION : Le Pseudomonas aeruginosa est un pathogène nosocomial important. La présente étude visait à évaluer le profil de susceptibilité antimicrobienne d'isolats de $P$ aeruginosa obtenus de patients dans différents secteurs d'hôpitaux canadiens.

MÉTHODOLOGIE : De janvier à décembre 2007 inclusivement, 12 hôpitaux sentinelles du Canada ont soumis des isolats cliniques de patients ayant fréquenté l'urgence, les services médicaux, les salles de chirurgie et les unités de soins intensifs (USI) dans le cadre de l'étude CANWARD 2007 sur la surveillance des services aux hospitalisés canadiens. Chaque centre était invité à soumettre des isolats cliniques (consécutifs, un par foyer d'infection du patient) provenant d'infections sanguines $(n=360)$, respiratoires $(n=200)$, urinaires $(n=100)$ et de plaies ou intraveineuses $(n=50)$. On a évalué le test de susceptibilité au moyen de la méthode de microdilution en milieu liquide du Clinical and Laboratory Standards Institute. On obtenait le type d'isolats multirésistants (résistance conjointe à au moins trois classes d'antimicrobiens) par électrophorèse en champ pulsé.

RÉSULTATS : Au total, on a prélevé 451 isolats de $P$ aeruginosa (représentant $7 \%$ de tous les isolats de l'étude CANWARD 2007). Le classement de la susceptibilité antimicrobienne (en pourcentage de susceptibilité) s'établissait comme suit : amikacine = pipéracillinetazobactam $(93,1 \%)>$ méropénem $(87,4 \%)>$ céfépime $(69,4 \%)>$ ciprofloxacine $(67,2 \%)>$ gentamicine $(66,1 \%)>$ lévofloxacine $(60,5 \%)$. On observait plus souvent une diminution de la susceptibilité à la céfépime, au méropénem et à la lévofloxacine dans les isolats de l'USI $(\mathrm{P}<0,05)$. Trente-quatre isolats $(7,5 \%)$ étaient multirésistants. Ces isolats étaient plus susceptibles de provenir d'un patient de l'USI $(\mathrm{P}=0,003)$ et moins susceptibles d'avoir été prélevés dans le sang $(\mathrm{P}=0,008)$. À l'exception de la colistine (polymyxine E), l'amikacine et la pipéracilline-tazobactam, suivies du méropénem, étaient les antimicrobiens les plus actifs à avoir été évalués contre les isolats multirésistants. Tous les isolats multirésistants étaient susceptibles à la colistine. La majorité des isolats multirésistants n'étaient pas liés génétiquement.

CONCLUSIONS : Le P aeruginosa est courant parmi les échantillons cliniques des patients des hôpitaux canadiens. Parmi les antimicrobiens antipseudomonaux évalués, l'amikacine, le méropénem et la pipéracillinetazobactam ont présenté la plus grande activité in vitro. Les isolats à la susceptibilité antimicrobienne réduite et les isolats multirésistants provenaient davantage de patients de l'USI. Tous les isolats multirésistants demeuraient susceptibles à la colistine.

${ }^{1}$ Departments of Medicine and Clinical Microbiology, Health Sciences Centre; ${ }^{2}$ Department of Medical Microbiology, Faculty of Medicine,

University of Manitoba; ${ }^{3}$ Nosocomial Infections Branch, National Microbiology Laboratory, Winnipeg, Manitoba

Correspondence: Dr Andrew Walkty, Health Sciences Centre, Department of Clinical Microbiology, MS673-820 Sherbrook Street, Winnipeg,

Manitoba R3A 1R9. Telephone 204-453-3867, fax 204-787-4699, e-mail awalkty@mts.net 
data, to guide empirical antimicrobial selection when treating infections where $P$ aeruginosa may be playing a role. The purpose of the present study was to determine the frequency with which $P$ aeruginosa isolates are obtained from patients in different areas of Canadian hospitals and to evaluate their antimicrobial susceptibility profiles.

\section{METHODS}

\section{Bacterial isolates}

Twelve sentinel hospital sites located in major population centres in 7 of the 10 provinces in Canada participated in the Canadian Ward Surveillance Study (CANWARD 2007). These sites were geographically distributed in a population-based fashion. From January through December 2007, inclusive, each study site was asked to submit clinical isolates (consecutive, one per patient per infection site) from inpatients and outpatients with respiratory $(n=200)$, urine $(n=100)$, wound/intravenous $(n=50)$ and bloodstream $(\mathrm{n}=360)$ infections. Hospital clinic isolates were subsequently excluded from the current analysis, due to the variable nature of where the isolates came from and their vastly different antimicrobial susceptibility profiles.

Only isolates that were deemed clinically significant were submitted. Limited demographic information was collected for each isolate (patient age, patient sex, hospital ward, specimen site, region of Canada). Isolate identification was performed by the submitting site using local criteria. Where indicated, identification was confirmed at the reference site. Isolates were shipped on Amies semi-solid transport media to the coordinating laboratory (Health Sciences Centre, Winnipeg, Manitoba), where they were then subcultured on appropriate media, and stocked in skim milk at $-80^{\circ} \mathrm{C}$.

\section{Antimicrobial susceptibilities}

Following two subcultures from frozen stock, the in vitro activity of common antipseudomonal antimicrobials was determined by broth microdilution in accordance with the Clinical and Laboratory Standards Institute guidelines $(4,5)$. For several antimicrobial classes (eg, carbapenems, cephalosporins), the in vitro activity of a single representative antimicrobial was assessed due to limited space on the susceptibility panels. Colistin (polymyxin E) susceptibility was evaluated for multidrug-resistant (MDR) isolates. Minimum inhibitory concentration interpretive standards for all antimicrobials were defined according to Clinical and Laboratory Standards Institute breakpoints (4). MDR P aeruginosa isolates were defined as isolates demonstrating resistance to antimicrobials from three or more different classes. The number that appears in the following text and tables after the MDR designation indicates the number of different classes to which isolates were resistant (eg, MDR3 indicates $P$ aeruginosa isolates that were resistant to at least one antimicrobial agent from three different classes). For the purpose of the present report the four antimicrobial classes considered were aminoglycosides (amikacin, gentamicin), fluoroquinolones (ciprofloxacin, levofloxacin), cefepime and piperacillin/tazobactam (considered together as one class), and carbapenems (meropenem). Colistin was not used in the classification of MDR isolates.

\section{Pulsed-field gel electrophoresis}

The genetic relationships among MDR $P$ aeruginosa isolates were assessed by pulsed-field gel electrophoresis, developed from a previously described method (6). This method was altered in the following ways; restriction of samples used 40 units of SpeI and switch times were changed to $5.3 \mathrm{~s}$ to $34.9 \mathrm{~s}$ with a run time of $21 \mathrm{~h}$. Fingerprints were analyzed using BioNumerics version 3.5 software (Applied Maths Inc, USA).

\section{Statistical analysis}

Statistical analysis was performed using JMP software, version 7.0 (SAS Institute Inc, USA). A logistic regression model was used to determine whether any of the baseline demographic variables recorded in the present study (specimen source, hospital ward, patient age, patient sex, region of Canada) were associated with either the MDR phenotype or individual antimicrobial resistance (association assessed for hospital ward only). A P of $\leq 0.05$ was considered significant.

\section{RESULTS}

In total, $451 \mathrm{P}$ aeruginosa isolates were collected as a part of CANWARD (specimen source: respiratory [50.1\%], blood [30.6\%], wound [10.6\%], urine [8.6\%]; ward type: medical [43.0\%], emergency room [22.4\%], intensive care unit [ICU] [23.1\%], surgical [11.5\%]). P aeruginosa accounted for 7\% (451 of 6471) of all isolates, making it the fourth most common organism obtained from patients in Canadian hospitals (third most common organism from medical wards, fourth from surgical wards and ICUs, fifth from emergency rooms). Susceptibility data for common antipseudomonal antimicrobials are presented in Table 1. The rank order of antimicrobial susceptibility was as follows (percent susceptible): amikacin $(93.1 \%)=$ piperacillin/tazobactam $(93.1 \%)>$ meropenem $(87.4 \%)>$ cefepime $(69.4 \%)>$ ciprofloxacin $(67.2 \%)>$ gentamicin $(66.1 \%)>$ levofloxacin $(60.5 \%)$. Table 2 presents a breakdown of antimicrobial susceptibility by hospital ward type. Isolates demonstrating reduced susceptibility to cefepime, meropenem and levofloxacin were more frequently obtained from patients in an ICU setting ( $\mathrm{P}<0.05$ in all cases).

Thirty-four MDR P aeruginosa isolates were collected as a part of CANWARD (7.5\% of all $P$ aeruginosa isolates). The MDR isolate demographics are presented in Table 3. MDR isolates were more commonly obtained from patients in an ICU setting $(P=0.003$, Table 3$)$ and less commonly obtained from a bloodstream source of infection $(\mathrm{P}=0.008$, Table 3$)$. Excluding colistin, amikacin and piperacillin/tazobactam, followed by meropenem, were the most active antimicrobials evaluated versus the MDR isolates (Table 1). As a class, fluoroquinolones demonstrated the lowest susceptibility rates against the MDR isolates. None of the 34 MDR isolates were fully susceptible to levofloxacin and only one (2.9\%) was fully susceptible to ciprofloxacin. All of the MDR isolates were susceptible to colistin. The various combinations of antimicrobial class resistance that contributed to the MDR phenotype are presented in Table 4. Among MDR3 isolates, resistance was most frequently observed to the combination of fluoroquinolones, aminoglycosides and piperacillin/cefepime (Table 4).

A pulsed-field gel electrophoresis dendrogram for the MDR isolates is provided (Figure 1). Although the majority of MDR isolates were genetically unrelated, three small clusters of related isolates ( $80 \%$ or greater homology) were observed. This included one cluster consisting of two isolates, one cluster containing three isolates, and a larger cluster of six genetically related isolates. Isolates in the latter cluster were collected from 
TABLE 1

Antimicrobial susceptibility of 451 Pseudomonas aeruginosa isolates obtained from Canadian patients

\begin{tabular}{|c|c|c|c|c|c|c|c|c|c|c|}
\hline \multirow[b]{3}{*}{ Antimicrobial } & \multicolumn{7}{|c|}{ All isolates $(n=451)$} & \multicolumn{3}{|c|}{ MDR isolates $(n=34)$} \\
\hline & \multicolumn{3}{|c|}{ Breakpoint interpretations, \% } & \multicolumn{2}{|c|}{ MIC $(\mu \mathrm{g} / \mathrm{mL})$} & \multicolumn{2}{|c|}{ Range of values } & \multirow{2}{*}{$\frac{\text { MDR3 }(n=23)}{\% ~ S}$} & \multirow{2}{*}{$\frac{\text { MDR4 }(n=11)}{\% ~ S}$} & \multirow{2}{*}{$\begin{array}{c}\text { All MDR }(n=34) \\
\% \text { S }\end{array}$} \\
\hline & $\mathrm{S}$ & I & $\mathbf{R}$ & $\mathrm{MIC}_{50}$ & $\mathrm{MIC}_{90}$ & Min & $\operatorname{Max}$ & & & \\
\hline Amikacin & 93.1 & 4.2 & 2.7 & 8 & 16 & $\leq 2$ & $>64$ & 60.9 & 54.5 & 58.8 \\
\hline Cefepime & 69.4 & 21.3 & 9.3 & 4 & 16 & $\leq 0.25$ & $>128$ & 0.0 & 0.0 & 0.0 \\
\hline Ciprofloxacin & 67.2 & 10.4 & 22.4 & 0.5 & 16 & $\leq 0.06$ & $>16$ & 4.3 & 0.0 & 2.9 \\
\hline Colistin & nd & nd & nd & nd & nd & nd & nd & 100.0 & 100.0 & 100.0 \\
\hline Gentamicin & 66.1 & 18.8 & 15.1 & 4 & 16 & $\leq 0.5$ & $>32$ & 4.3 & 0.0 & 2.9 \\
\hline Levofloxacin & 60.5 & 14.4 & 25.1 & 1 & 32 & $\leq 0.06$ & $>32$ & 0.0 & 0.0 & 0.0 \\
\hline Meropenem & 87.4 & 4.4 & 8.2 & 0.5 & 8 & $\leq 0.06$ & $>64$ & 43.5 & 0.0 & 29.4 \\
\hline Piperacillin/ & 93.1 & na & 6.9 & 4 & 64 & $\leq 1$ & 512 & 52.2 & 63.6 & 55.9 \\
\hline
\end{tabular}

Tazobactam

Breakpoint interpretations: Amikacin Susceptible (S) $\leq 16 \mu \mathrm{g} / \mathrm{mL} ;$ Intermediate (I) $=32 \mu \mathrm{g} / \mathrm{mL} ;$ Resistant (R) $\geq 64 \mu \mathrm{g} / \mathrm{mL} ;$ Cefepime S $\leq 8 \mu \mathrm{g} / \mathrm{mL} ; \mathrm{I}=16 \mu \mathrm{g} / \mathrm{mL} ; \mathrm{R} \geq 32 \mu \mathrm{g} / \mathrm{mL}$; Ciprofloxacin $S \leq 1 \mu \mathrm{g} / \mathrm{mL} ; \mathrm{l}=2 \mu \mathrm{g} / \mathrm{mL} ; R \geq 4 \mu \mathrm{g} / \mathrm{mL}$; Colistin $S \leq 2 \mu \mathrm{g} / \mathrm{mL} ;$ I $=4 \mu \mathrm{g} / \mathrm{mL} ; R \geq 8 \mu \mathrm{g} / \mathrm{mL}$; Gentamicin $S \leq 4 \mu \mathrm{g} / \mathrm{mL} ; \mathrm{I=}=8 \mathrm{~g} / \mathrm{mL} ; R \geq 16 \mu \mathrm{g} / \mathrm{mL} ;$ Levofloxacin $S \leq 2 \mu \mathrm{g} / \mathrm{mL}$; I=4 $\mu \mathrm{g} / \mathrm{mL} ; R \geq 8 \mu \mathrm{g} / \mathrm{mL}$; Meropenem S $\leq 4 \mu \mathrm{g} / \mathrm{mL} ; \mathrm{I}=8 \mu \mathrm{g} / \mathrm{mL} ; R \geq 16 \mu \mathrm{g} / \mathrm{mL}$; Piperacillin/Tazobactam S $\leq 64 / 4 \mu \mathrm{g} / \mathrm{mL} ; R \geq 128 / 4 \mu \mathrm{g} / \mathrm{mL}$. Max Maximum; MDR Multidrugresistant (the number that appears after the MDR designation indicates the number of different antimicrobial classes to which isolates are resistant, eg, MDR3 indicates $P$ aeruginosa isolates that are resistant to at least one antimicrobial agent from three different classes); MIC Minimum inhibitory concentration; $M C_{50 / 90}$ MICs needed to inhibit 50\%/90\% of organisms; Min Minimum; na Not applicable; nd No data

TABLE 2

Antimicrobial susceptibility of 451 Pseudomonas aeruginosa isolates, stratified by hospital ward type

\begin{tabular}{lccccc}
\hline & \multicolumn{3}{c}{ \% Susceptible* (n/total) } & \\
\cline { 2 - 4 } Antimicrobial & Emergency & Surgical & Medical & \\
\hline Isolates, $\mathrm{n}$ & 101 & ward & ward & ICU & P \\
Amikacin & 94.1 & 94.2 & 92.8 & 92.3 & 0.945 \\
Cefepime & $(95 / 101)$ & $(49 / 52)$ & $(180 / 194)$ & $(96 / 104)$ & \\
& 80.2 & 75.0 & 70.1 & 54.8 & 0.003 \\
Ciprofloxacin & $(81 / 101)$ & $(39 / 52)$ & $(136 / 194)$ & $(57 / 104)$ & \\
& 78.2 & 73.1 & 61.9 & 63.5 & 0.038 \\
Gentamicin & $(79 / 101)$ & $(38 / 52)$ & $(120 / 194)$ & $(66 / 104)$ & \\
Levofloxacin & 70.3 & 67.3 & 66.0 & 61.5 & 0.619 \\
& $(71 / 101)$ & $(35 / 52)$ & $(128 / 194)$ & $(64 / 104)$ & \\
Meropenem & 76.2 & 67.3 & 56.2 & 50.0 & 0.001 \\
& $(77 / 101)$ & $(35 / 52)$ & $(109 / 194)$ & $(52 / 104)$ & \\
Piperacillin/ & 95.0 & 90.4 & 89.7 & 74.0 & $<0.0001$ \\
Tazobactam & $(96 / 101)$ & $(47 / 52)$ & $(174 / 194)$ & $(77 / 104)$ & \\
\hline Breakpoint & 97.0 & 92.3 & 93.8 & 88.5 & 0.105 \\
& $(98 / 101)$ & $(48 / 52)$ & $(182 / 194)$ & $(92 / 104)$ & \\
\hline
\end{tabular}

${ }^{*}$ Breakpoint interpretation: Amikacin Susceptible (S) $\leq 16 \mu \mathrm{g} / \mathrm{mL}$; Cefepime $S \leq 8 \mu \mathrm{g} / \mathrm{mL}$; Ciprofloxacin $S \leq 1 \mu \mathrm{g} / \mathrm{mL}$; Gentamicin $S \leq 4 \mu \mathrm{g} / \mathrm{mL}$; Levofloxacin $S \leq 2 \mu \mathrm{g} / \mathrm{mL}$; Meropenem $S \leq 4 \mu \mathrm{g} / \mathrm{mL}$; Piperacillin/Tazobactam $S \leq 64 / 4 \mu \mathrm{g} / \mathrm{mL}$. ICU Intensive care unit

bloodstream, respiratory and wound specimens, and were all isolated from patients at a single institution in Ontario (data not shown).

\section{DISCUSSION}

The data presented here serve to confirm the continued importance of $P$ aeruginosa as a pathogen in nosocomial infections. These data are in agreement with several previously published surveillance studies describing the frequency of occurrence of $P$ aeruginosa among clinical samples obtained from patients in a hospital setting (1,7-9). Among the antipseudomonal antimicrobial agents evaluated here, amikacin, meropenem and piperacillin/tazobactam were the most active, while the fluoroquinolones were the least active. These results are consistent with surveillance data from the United States (10). Variation in the definition of MDR precludes a

\section{TABLE 3}

Demographic information for 34 multidrug-resistant (MDR) Pseudomonas aeruginosa isolates obtained from patients in Canadian hospitals

\begin{tabular}{|c|c|c|c|c|}
\hline \multirow[b]{2}{*}{ Demographics } & \multirow[b]{2}{*}{$\begin{array}{l}\text { Total number } \\
\text { of isolates }\end{array}$} & \multicolumn{3}{|c|}{ MDR group* } \\
\hline & & $\begin{array}{c}\text { MDR3, \% } \\
\text { (n/total) }\end{array}$ & $\begin{array}{c}\text { MDR4, \% } \\
\text { (n/total) }\end{array}$ & $\begin{array}{c}\text { MDR } \geq 3, \% \\
\text { (n/total) }\end{array}$ \\
\hline \multicolumn{5}{|l|}{ Specimen source } \\
\hline Respiratory & 226 & $5.3(12 / 226)$ & $2.7(6 / 226)$ & $8.0(18 / 226)$ \\
\hline Blood & 138 & $2.2(3 / 138)$ & $1.4(2 / 138)$ & $3.6(5 / 138)$ \\
\hline Urine & 39 & $12.8(5 / 39)$ & $2.6(1 / 39)$ & $15.4(6 / 39)$ \\
\hline Wound & 48 & $6.3(3 / 48)$ & $4.2(2 / 48)$ & $10.4(5 / 48)$ \\
\hline$P$ & na & 0.021 & 0.5 & 0.008 \\
\hline \multicolumn{5}{|l|}{ Ward type } \\
\hline Surgical & 52 & $1.9(1 / 52)$ & $1.9(1 / 52)$ & $3.8(2 / 52)$ \\
\hline ER & 101 & $3.0(3 / 101)$ & $0.0(0 / 101)$ & $3.0(3 / 101)$ \\
\hline Medical & 194 & $5.7(11 / 194)$ & $1.5(3 / 194)$ & $7.2(14 / 194)$ \\
\hline $\mathrm{ICU}$ & 104 & 7.7 (8/104) & $6.7(7 / 104)$ & $14.4(15 / 104)$ \\
\hline$P$ & na & 0.159 & 0.006 & 0.003 \\
\hline \multicolumn{5}{|l|}{ Patient age, years } \\
\hline 17 and younger & 36 & $2.8(1 / 36)$ & $0.0(0 / 36)$ & $2.8(1 / 36)$ \\
\hline 18 to 64 & 186 & $6.5(12 / 186)$ & $4.3(8 / 186)$ & $10.8(20 / 186)$ \\
\hline 65 and older & 229 & $4.4(10 / 229)$ & $1.3(3 / 229)$ & $5.7(13 / 229)$ \\
\hline $\mathrm{P}$ & na & 0.324 & 0.087 & 0.037 \\
\hline \multicolumn{5}{|l|}{ Patient sex } \\
\hline Female & 172 & $4.7(8 / 172)$ & $2.9(5 / 172)$ & $7.6(13 / 172)$ \\
\hline Male & 279 & $5.4(15 / 279)$ & $2.2(6 / 279)$ & $7.5(21 / 279)$ \\
\hline $\mathrm{P}$ & na & 0.785 & 0.505 & 0.872 \\
\hline \multicolumn{5}{|l|}{ Region of Canada ${ }^{\dagger}$} \\
\hline Central & 154 & $4.5(7 / 154)$ & $3.9(6 / 154)$ & $8.4(13 / 154)$ \\
\hline West & 141 & $5.7(8 / 141)$ & $1.4(2 / 141)$ & $7.1(10 / 141)$ \\
\hline $\begin{array}{l}\text { Quebec/ } \\
\text { Maritimes }\end{array}$ & 156 & $5.1(8 / 156)$ & $1.9(3 / 156)$ & $7.1(11 / 156)$ \\
\hline $\mathrm{P}$ & na & 0.9 & 0.274 & 0.855 \\
\hline
\end{tabular}

${ }^{*}$ The number that appears after the MDR designation indicates the number of different antimicrobial classes to which isolates are resistant (eg, MDR3 indicates $P$ aeruginosa isolates that are resistant to at least one antimicrobial agent from three different classes); ${ }^{\dagger}$ Region of Canada: Central = Ontario; West = British Columbia, Alberta, Saskatchewan, Manitoba; Quebec/Maritimes = Quebec, Nova Scotia. ER Emergency room; ICU Intensive care unit; na Not applicable 
TABLE 4

Combinations of antimicrobial class resistance among 34 multidrug-resistant (MDR) Pseudomonas aeruginosa clinical isolates

\begin{tabular}{|c|c|c|c|c|c|c|c|}
\hline \multirow[b]{2}{*}{ MDR group* } & \multicolumn{4}{|c|}{ Antibiotic class } & \multirow[b]{2}{*}{ Isolates, n } & \multirow[b]{2}{*}{$\%$ of MDR group } & \multirow{2}{*}{$\begin{array}{c}\% \text { of all } P \text { aeruginosa } \\
\text { isolates }(n=451)\end{array}$} \\
\hline & Fluoroquinolone & Aminoglycoside & Piperacillin/Cefepime & Carbapenem & & & \\
\hline \multirow[t]{4}{*}{ MDR3 } & Resistant & Resistant & Resistant & & 12 & 52.2 & 2.7 \\
\hline & Resistant & & Resistant & Resistant & 5 & 21.7 & 1.1 \\
\hline & Resistant & Resistant & & Resistant & 5 & 21.7 & 1.1 \\
\hline & & Resistant & Resistant & Resistant & 1 & 4.3 & 0.2 \\
\hline Total & & & & & 23 & 100.0 & 5.1 \\
\hline MDR4 & Resistant & Resistant & Resistant & Resistant & 11 & 100.0 & 2.4 \\
\hline Total & & & & & 11 & 100.0 & 2.4 \\
\hline
\end{tabular}

*The number that appears after the MDR designation indicates the number of different antimicrobial classes to which isolates are resistant (eg, MDR3 indicates $P$ aeruginosa isolates that are resistant to at least one antimicrobial agent from three different classes)

meaningful comparison of our MDR rates with those reported in other publications. Our data indicate that the MDR P aeruginosa isolates circulating in Canada are, for the most part, genetically unrelated. These isolates therefore represent many individual unrelated organisms that have undergone extensive exposure to antimicrobials, allowing them to develop a MDR phenotype.

None of the MDR isolates evaluated in the current study were resistant to colistin, suggesting that this agent may have a role in the treatment of infections caused by MDR P aeruginosa. This observation is supported by an increasing number of reports demonstrating clinical efficacy of colistin in the treatment of MDR P aeruginosa infections (11).

It is interesting to note that MDR isolates and isolates with reduced susceptibility to certain antimicrobials (cefepime, levofloxacin, meropenem) were more commonly obtained from patients in an ICU setting. One may hypothesize that this observation could relate to higher levels of antimicrobial consumption and/or differences in the specific antimicrobials used in ICUs relative to other hospital locations.

There are several limitations to the data presented here. First of all, limited demographic information was collected on the patients from whom the isolates were obtained. As a consequence of this, it was not possible to assess in detail specific variables associated with the acquisition of MDR P aeruginosa. Additionally, we do not know how many isolates were obtained from patient groups at higher risk of infection with resistant $P$ aeruginosa (eg, cystic fibrosis patients). We cannot exclude the possibility that some of the resistance observed in the present study was being driven by isolates from very specific patient populations. Susceptibility testing was not performed for ceftazidime, tobramycin and imipenem due to lack of space on the susceptibility panels utilized. It is recognized that this data would be beneficial, because these antimicrobials may be a part of many hospital formularies. Up to $2.5 \%$ of isolates in the present study may have been submitted from duplicate patients (ie, two different isolates submitted from the same patient). Due to the rarity of this event, it is not believed that inclusion of these isolates had a significant impact on the susceptibility data described here. Finally, we did not investigate the molecular mechanisms conferring antimicrobial resistance among our isolates due to limited time and resources.

\section{CONCLUSIONS}

$P$ aeruginosa is commonly isolated from patients in Canadian hospitals. Of the antimicrobials evaluated, amikacin, meropenem

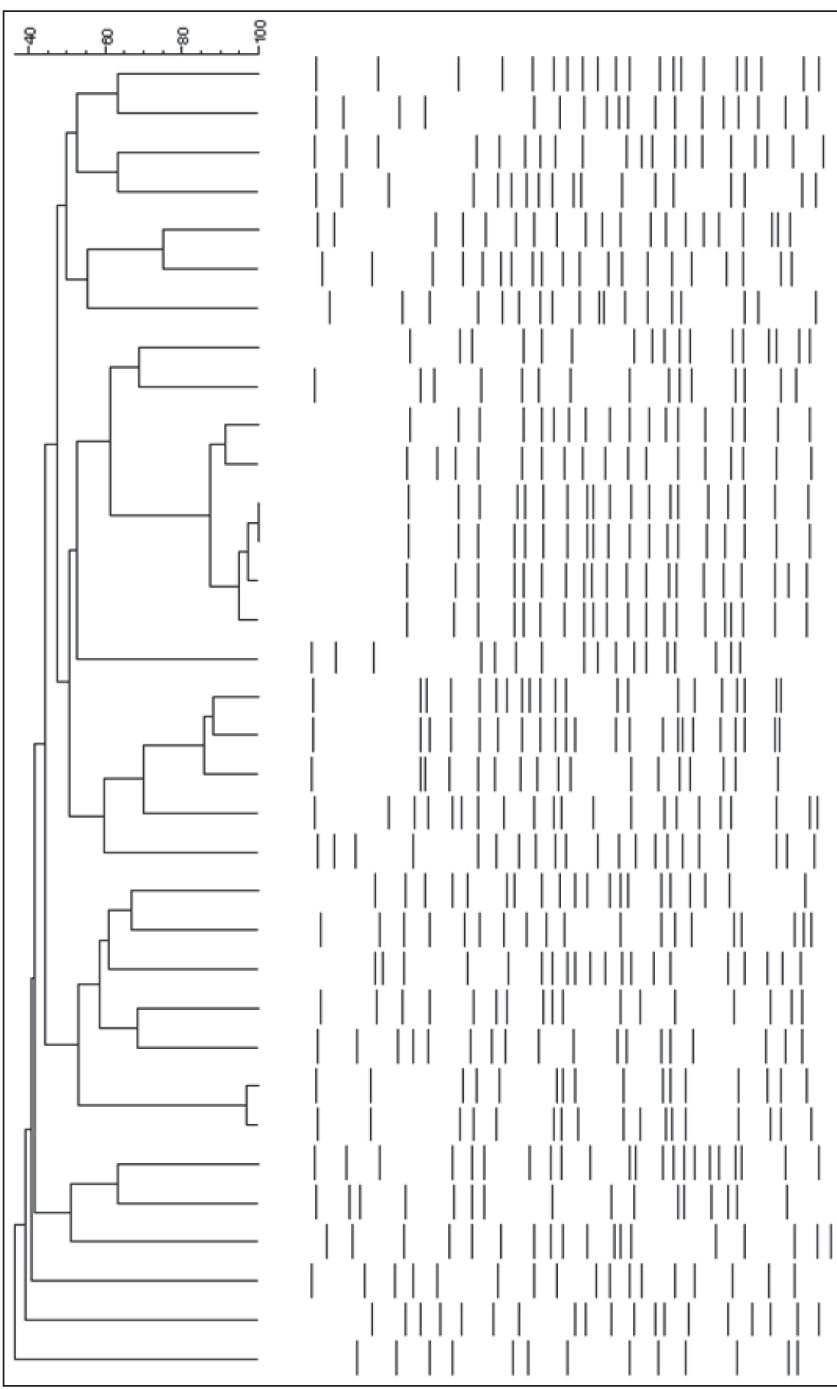

Figure 1) Dendrogram reflecting genetic relatedness among 34 multidrug-resistant Pseudomonas aeruginosa isolates

and piperacillin/tazobactam were the most active, while the fluoroquinolones were the least active. Thirty-four isolates (7.5\%) were MDR. Isolates with reduced susceptibility to individual antimicrobials and MDR isolates were more frequently obtained from patients in an ICU setting. All of the MDR isolates remained susceptible to colistin. 
The data presented here may assist clinicians in choosing appropriate empirical therapy for nosocomial infections where $P$ aeruginosa is thought to be playing a role. Given the high rates of antimicrobial resistance among $P$ aeruginosa isolates, new antimicrobials with antipseudomonal activity are desperately needed. A standardized definition of MDR for $P$ aeruginosa would facilitate comparison of MDR rates among studies.

ACKNOWLEDGEMENTS: The authors would like to thank the participating centres of CANWARD, investigators, and laboratory staff for their support. Funding for the CANWARD 2007 study was provided in part by the University of Manitoba, Health Sciences Center in Winnipeg, National Microbiology Laboratory-Health Canada, Abbott, Affinium Inc., Astellas, Bayer, Janssen Ortho Inc, Oryx, Pfizer Canada, TaiGen, Targanta, and Wyeth Inc.

\section{REFERENCES}

1. Gaynes R, Edwards JR, and the National Nosocomial Infections Surveillance System. Overview of nosocomial infections caused by Gram-negative bacilli. Clin Infect Dis 2005;41:848-54.

2. Livermore DM. Multiple mechanisms of antimicrobial resistance in Pseudomonas aeruginosa: Our worst nightmare? Clin Infect Dis 2002;34:634-40.

3. Micek ST, Lloyd AE, Ritchie DJ, Reichley RM, Fraser VJ, Kollef MH. Pseudomonas aeruginosa bloodstream infection: Importance of appropriate initial antimicrobial treatment. Antimicrob Agents Chemother 2005;49:1306-11.
4. Clinical and Laboratory Standards Institute. Performance Standards for Antimicrobial Susceptibility Testing: Seventeenth Informational Supplement M100-S17. CLSI, Wayne, PA, USA, 2007.

5. Clinical and Laboratory Standards Institute. Methods for Dilution Antimicrobial Susceptibility Tests for Bacteria That Grow Aerobically - Seventh Edition: Approved Standard M7-A7. CLSI, Wayne, PA, USA, 2006.

6. Mulvey MR, Bryce E, Boyd D, et al. Ambler class A extendedspectrum beta-lactamase-producing Escherichia coli and Klebsiella spp. in Canadian hospitals. Antimicrob Agents Chemother 2004:48:1204-14.

7. Biedenbach DJ, Moet GJ, Jones RN. Occurrence and antimicrobial resistance pattern comparisons among bloodstream infection isolates from the SENTRY antimicrobial surveillance program (1997-2002). Diagn Microbiol Infect Dis 2004;50:59-69.

8. Hoban DJ, Biedenbach DJ, Mutnick AH, Jones RN. Pathogen of occurrence and susceptibility patterns associated with pneumonia in hospitalized patients in North America: Results of the SENTRY antimicrobial surveillance study (2000). Diagn Microbiol Infect Dis 2003;45:279-85.

9. Mathai D, Jones RN, Pfaller MA, the SENTRY Participant Group North America. Epidemiology and frequency of resistance among pathogens causing urinary tract infections in 1,510 hospitalized patients: A report from the SENTRY antimicrobial surveillance program (North America). Diagn Microbiol Infect Dis 2001;40:129-36.

10. Karlowsky JA, Draghi DC, Jones ME, Thornsberry C, Friedland IR, Sahm DF. Surveillance for antimicrobial susceptibility among clinical isolates of Pseudomonas aeruginosa and Acinetobacter baumannii from hospitalized patients in the United States, 1998 to 2001. Antimicrob Agents Chemother 2003;47:1681-8.

11. Li J, Nation RL, Turnidge JD, et al. Colistin: the re-emerging antibiotic for multidrug-resistant Gram-negative bacterial infections. Lancet Infect Dis 2006;6:589-601. 


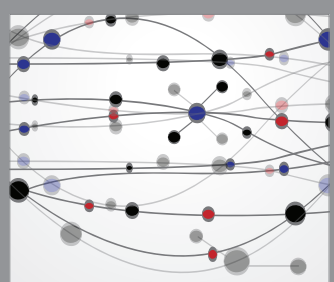

The Scientific World Journal
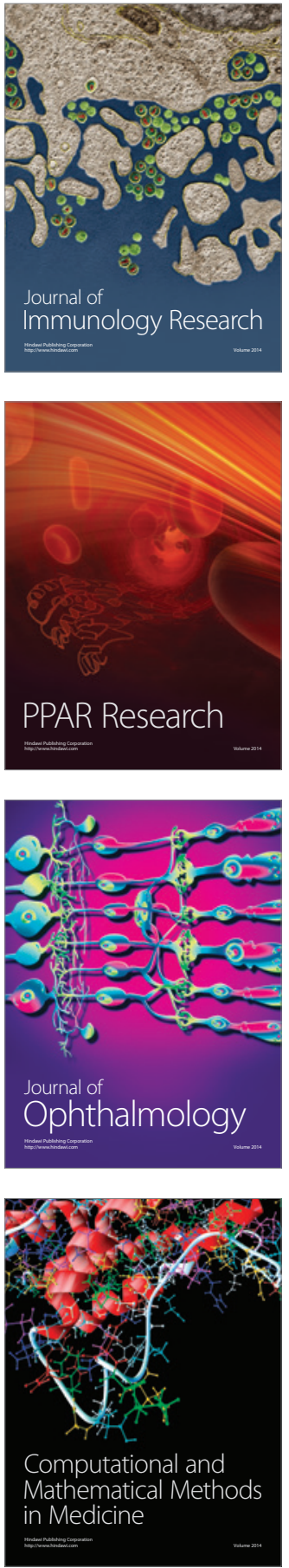

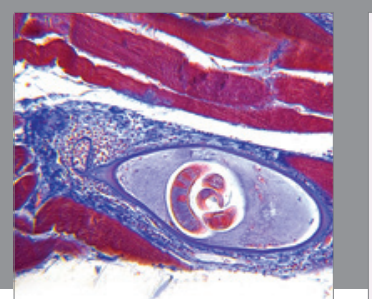

Gastroenterology Research and Practice

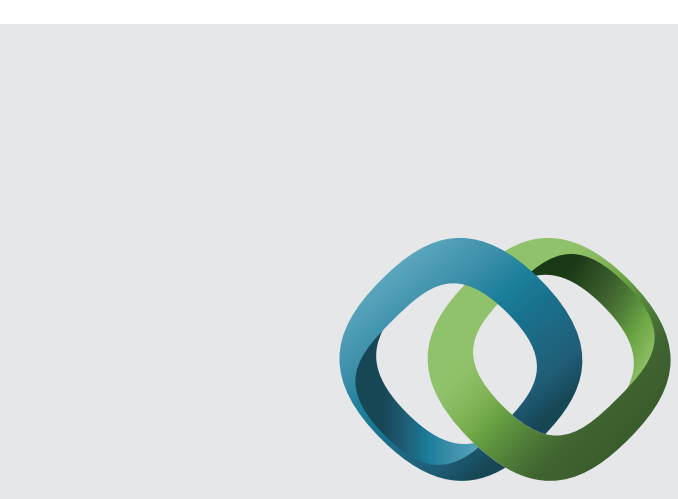

\section{Hindawi}

Submit your manuscripts at

http://www.hindawi.com
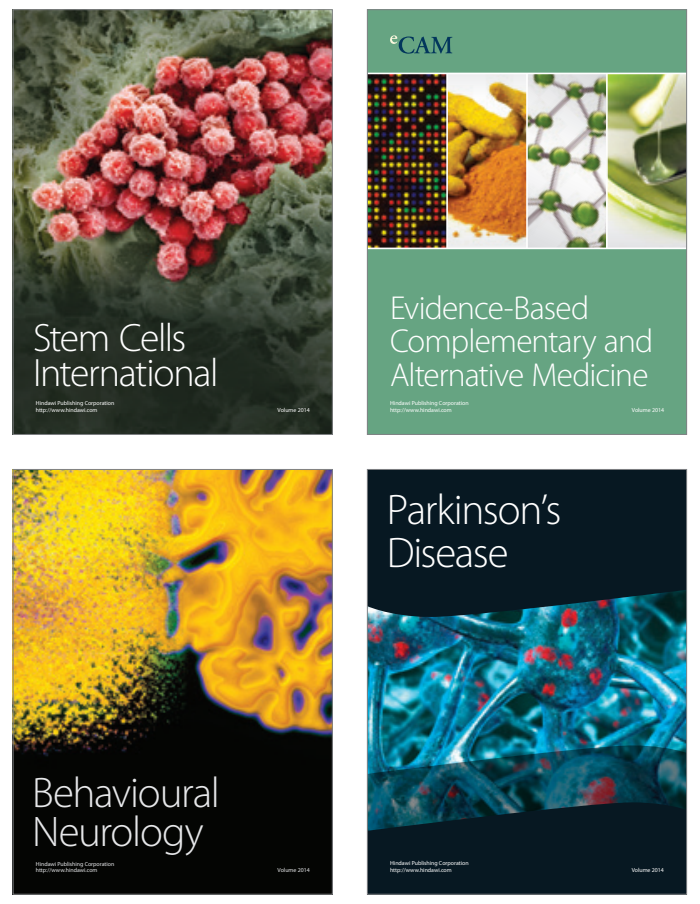
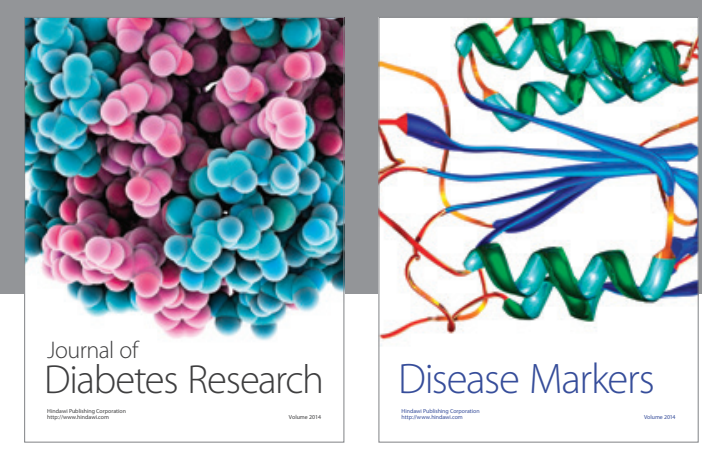

Disease Markers
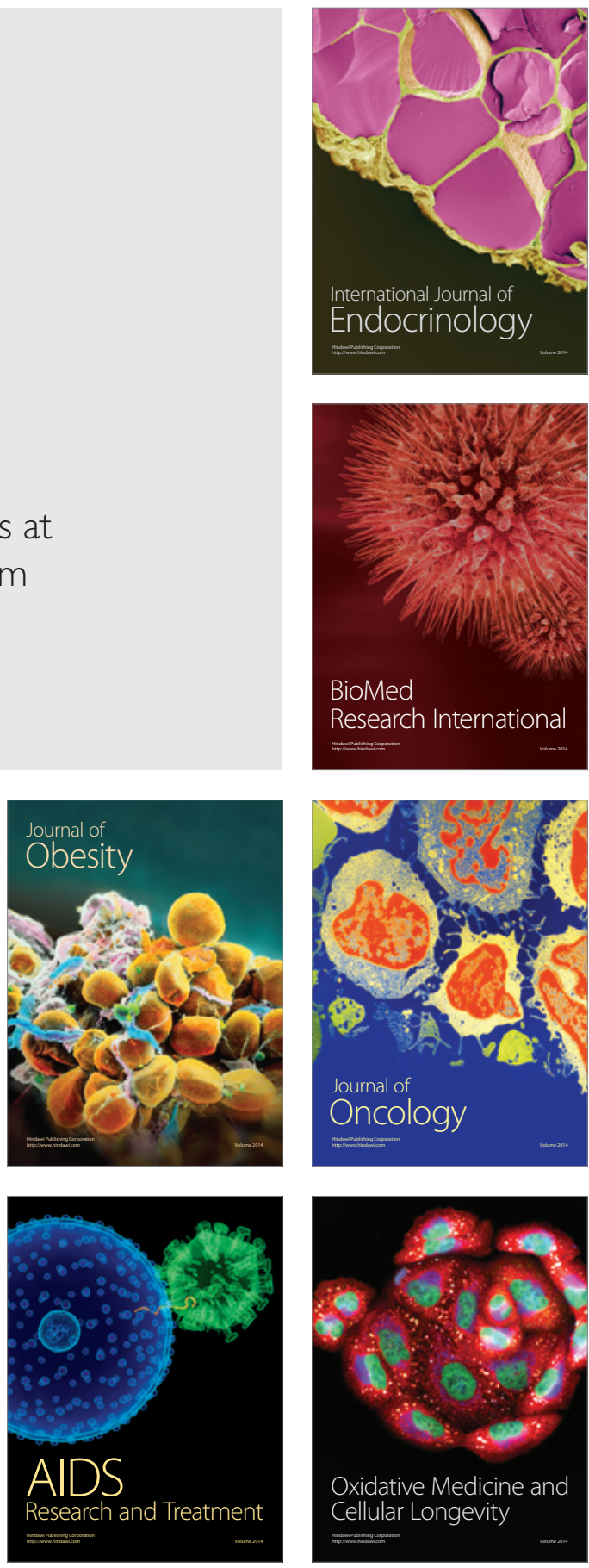